\title{
Relationship between fluid-attenuated inversion-recovery (FLAIR) signal intensity and inflammatory mediator's levels in the hippocampus of patients with temporal lobe epilepsy and mesial temporal sclerosis
}

\author{
Pedro Paulo Vasconcellos Varella', Joselita Ferreira Carvalho Santiago ${ }^{1}$, \\ Henrique Carrete Jr. ${ }^{2}$, Elisa Mieko Suemitsu Higa ${ }^{3}$, \\ Elza Márcia Targas Yacubian', Ricardo Silva Centeno, \\ Luís Otávio Sales Ferreira Caboclo', Eduardo Ferreira de Castro Neto', \\ Mauro Canzian", Débora Amado', Esper Abrão Cavalheiro', \\ Maria da Graça Naffah- Mazzacoratti ${ }^{1,5}$
}

\begin{abstract}
We investigated a relationship between the FLAIR signal found in mesial temporal sclerosis (MTS) and inflammation. Twenty nine patients were selected through clinical and $\mathrm{MRI}$ analysis and submitted to cortico-amygdalo-hippocampectomy to seizure control. Glutamate, TNF $\alpha, I L 1$, nitric oxide (NO) levels and immunostaining against IL1 $\beta$ and CD45 was performed. Control tissues $(n=10)$ were obtained after autopsy of patients without neurological disorders. The glutamate was decreased in the temporal lobe epilepsy (TLE) -MTS group ( $p<0.001)$, suggesting increased release of this neurotransmitter. The IL1 $\beta$ and TNF $\alpha$ were increased in the hippocampus $(p<0.05)$ demonstrating an active inflammatory process. A positive linear correlation between FLAIR signal and NO and IL1 $\beta$ levels and a negative linear correlation between FLAIR signal and glutamate concentration was found. Lymphocytes infiltrates were present in hippocampi of TLE patients. These data showed an association between hippocampal signal alteration and increased inflammatory markers in TLE-MTS.
\end{abstract}

Key words: FLAIR hippocampal signal, cytokines, NO, glutamate and hippocampal sclerosis.

Correlação da intensidade do sinal em FLAIR e os níveis de mediadores inflamatórios no hipocampo de pacientes com epilepsia do lobo temporal e esclerose mesial temporal

Correspondence

Maria da Graça Naffah Mazzacoratti Rua Botucatu 862 04023-900 São Paulo SP - Brasil E-mail: naffahmazz.nexp@epm.br

\section{Support}

CInNAPCe (FAPESP), CAPES,

CNPq, MCT (Instituto Nacional de Neurociência Translacional (INNT)

Received 20 January 2010

Received in final form 23 July 2010 Accepted 2 August 2010

\section{RESUMO}

Este estudo foi delineado para investigar a presença de relação entre a intensidade de sinal em FLAIR e níveis de citocinas, óxido nítrico (NO) e glutamato no hipocampo de pacientes com epilepsia do lobo temporal refratária, associada com esclerose mesial (TLE-MTS). Vinte e nove pacientes foram selecionados através de análise clínica e de ressonância magnética (RM) que foram submetidos a cortico-amigdalo-hipocampectomia para o controle das crises. Os níveis de glutamato foram avaliados por HPLC, as citocinas TNF $\alpha$ e IL1 $\beta$ por

${ }^{1}$ Neurology/ Neurosurgery Department, UNIFESP, São Paulo SP, Brazil; ${ }^{2}$ Diagnosis and Image Department, UNIFESP, São Paulo SP, Brazil; ${ }^{3}$ Medicine Department, UNIFESP, São Paulo SP, Brazil; ${ }^{4}$ Hearth Institute, University of São Paulo, São Paulo SP, Brazil; ${ }^{5}$ Biochemistry Department, UNIFESP, São Paulo SP, Brazil. 
ELISA e os níveis de NO via NO system. Avaliamos também por imuno-histoquímica a expressão de IL1 $\beta$ e CD45 em tecidos controles e com esclerose. Tecido controle foi obtido após autópsia de indivíduos mortos sem disfunções inflamatórias e neurológicas ( $n=10)$. A concentração de glutamato se mostrou reduzida no tecido TLE-MTS $(p<0,001)$ sugerindo aumento na liberação desse neurotransmissor. TNF $\alpha$ e IL1 $\beta$ também apresentaram níveis elevados no hipocampo dos pacientes $(p<0,05)$, demonstrando um processo inflamatório crônico. Houve uma correlação linear positiva entre a intensidade do sinal em FLAIR e os níveis de NO e IL1 $\beta$. Em contraste, uma correlação linear negativa foi encontrada entre a intensidade do sinal em FLAIR e níveis de glutamato no hipocampo com esclerose. Infiltrado linfocitário hipocampal também foi visualizado pela imuno-marcação com CD45 em pacientes com TLE-MTS. Esses dados mostraram uma associação entre alteração de sinal na RM e marcadores inflamatórios em pacientes com TLE-MTS.

Palavras-chave: sinal hipocampal em FLAIR, citocinas, NO, glutamato, esclerose hipocampal.

Temporal lobe epilepsy (TLE) represents a severe common syndrome in patients presenting refractory seizures. Atrophy and/or signal changes of the hippocampus have been described as the most reliable magnetic resonance imaging (MRI) inclusion criteria in mesial temporal sclerosis (MTS). These alterations are the most frequent pathological findings presented by these patients ${ }^{1}$. In addition ipsilateral temporal pole signal and volume abnormalities are described as part of the spectrum of MRI features in cases of MTS $^{2}$. The hippocampal sclerosis (HS) is also known as Ammon's horn sclerosis and includes selective hippocampal cell loss, gliosis and synaptic reorganization as the mossy fibers sprouting ${ }^{3,4}$. Indeed, HS is seen as loss of volume, decreased T1 and increased T2 signals on views through the structure, associated with ipsilateral temporal lobe atrophy and significant asymmetry of hippocampal volume ${ }^{5,6}$. The predominant cell loss occurs in pyramidal neurons of the stratum pyramidale of Ammon's horn. Neuronal population of the stratum oriens survives in most sclerotic hippocampi, along with interneurons scattered throughout the neuron-depleted pyramidal layer. In the dentate gyrus, many of the granule cells are lost and neurons in the granule cell layer appear to be more dispersed. Thus, several lines of evidence point to sclerotic hippocampus as the major structure involved in chronic seizures observed in MTS, for review, $\mathrm{see}^{7}$. As reported by Bernasconi et al. ${ }^{8}$ the hippocampal head is more atrophic than hippocampal body and tail, between other structures also involved such as amygdala, entorhinal and perihinal cortices.

The immune system and associated inflammatory process play important function in the protection and repair of several tissues, thus constituting an adaptive, beneficial endogenous response. In contrast, immune response activation can also be a direct or indirect cause of neuronal dysfunctions. During inflammatory process the communication between cells of the immune system oc- curs either via direct cell-to-cell contact or via soluble factors called cytokines such as IL1 $\beta$, IL6 and TNF $\alpha^{9}$. Deleterious effects of cytokines on neuronal survival are likely to be mediated by their ability to provoke an extracellular increase of glutamate by acting on the mechanisms of its release and reuptake, potentiating the function of ionotropic glutamate receptors ${ }^{10}$, enhancing the production of mediators of oxidative stress ${ }^{11}$.

In the same direction, nitric oxide (NO) production increases in neurodegenerative diseases as consequence of oxidative stress. NO synthesis is activated in cerebral diseases by the release of glutamate combined with inhibition of glutamate removal, which leads to N-methyl-Daspartate (NMDA) receptor over activation and excess $\mathrm{Ca}^{++}$influx into neurons ${ }^{12}$. It is believed that the toxic effect of NO results from the action of its downstream metabolite, ONOO-, which is a highly reactive, formed when NO reacts with superoxide radicals, which also regulate excitotoxicity and induce oxidative DNA, damage ${ }^{13}$. Excitotoxicity due excessive glutamate receptors activation is also associated with osmotic imbalance, when countered by an influx of $\mathrm{Na}^{+}, \mathrm{Cl}^{-}$and water. This situation conduces to cell edema with eventual plasma membrane rupture and cell death ${ }^{12,14-16}$

In this context, the present work was delineated to study a possible correlation between the alteration of the signal in the head, body and tail of the hippocampus obtained after fluid-attenuated inversion-recovery (FLAIR) MRI analysis and the levels of IL1 $\beta$, TNF $\alpha$, glutamate and NO in patients with TLE and MTS submitted to cortico-amygdalo-hippocampectomy to seizure control. Thus, we hypothesize that the inflammatory process associated with excitotoxicity in the hippocampus could be responsible for the alteration of signal found in MRI analysis of patients with TLE

In this work we also investigated a possible involvement of both hemispheres in TLE associated to MTS an- 
alyzing the intensity of the ipsilateral signal (hippocampal sclerosis) versus the contralateral signal, from each patient. The relationship between the levels of IL1 $\beta$, $\mathrm{TNF} \alpha$, glutamate and $\mathrm{NO}$ with the type of sclerosis using Blumcke citeria ${ }^{17}$ was also investigated. Furthermore, immuno-histochemistry against IL1 $\beta$, TNF $\alpha$ and CD45 in autopsy/control and sclerotic tissues was also performed to localize and identify cellular and humoral components of immune system.

\section{METHOD}

All experiments were performed under approval from the Institutional Ethics Committee of the Universidade Federal de São Paulo (UNIFESP). Surgical specimens from patients with intractable epilepsy were submitted to standard cortico-amygdalo-hippocampectomy at the Hospital São Paulo (UNIPETE/SPDM-UNIFESP-EPM, Brazil). All cases showing neoplasm, vascular malformations, post-traumatic and ischemic lesions on preoperative MRI were excluded. Selected patients $(n=29)$ had detailed anamnesis, video-EEG recordings and MRI studies and after these procedures the epileptogenic zone was delineated. The age of the patients with TLE and HS varied from 19 to 56 years ( $36.9 \pm 9$ years) and this group was composed by $72.4 \%$ of women and $27.6 \%$ of men.

The drugs used by these patients for seizure control include: carbamazepine, phenobarbital, diphenylhydantoin, clobazam, valproate and topiramate. Control hippocampi were obtained from brains showing no evidence of pathology on the basis of gross and routine histological examination removed from autopsies (less than $6 \mathrm{~h}$ of postmortem period). The age of the subjects at death varied from 38 to 84 years $(67 \pm 12$ years) $(n=10)$. This last group was also composed by $60 \%$ of women and $40 \%$ of men (autopsy/control).

Thus, the levels of IL1 $\beta$, TNF $\alpha$, glutamate and NO were measured in the head of hippocampi and correlated with the FLAIR MRI signal, obtained in the head, body and tail of this structure. We also compared IL1 $\beta$, TNF $\alpha$, glutamate concentration in the hippocampi of patients with HS with those found in control tissues, in similar hippocampal areas, removed during the autopsy of patients, without neurological disease (autopsy/control). We did not compare NO levels from autopsy/control tissue and those obtained from hippocampi of our patients since autopsy tissue is not an appropriate control. The postmortem levels of NO increases after death due to polyamines production and anoxia ${ }^{14,15}$ and several works have reported arterial synthesis of $\mathrm{NO}$ after death ${ }^{16}$.

The autopsies were made by a pathologist from Pathological Anatomic Department Incor, FMUSP, especially trained for this purpose. Thus, the pathologist was able to remove the same structures as performed by the neuro- surgeon. Using this procedure, similar hippocampal areas from epileptic patients and autopsied subjects could be compared. All patients and families had signed the consent term authorizing the tissues utilization.

\section{MRI acquisition}

Patients with clinical diagnostic of TLE and control subjects were underwent imaging with a 1.5-T Gyroscan (Philips Medical System, Eindhoven, The Netherlands) using a standard head coil. The protocol included the following: sagittal T1-weighted (repetition time $[\mathrm{TR}]=433$ milliseconds, echo time $[\mathrm{TE}]=13$ milliseconds, field of view $[\mathrm{FOV}]=25 \mathrm{~cm}, 6 \mathrm{~mm}$ slice thickness, matrix size $=256 \times 512$ ); axial turbo-spin echo FLAIR-weighted ( $\mathrm{TR}=4535$ milliseconds, $\mathrm{TE}=100$ milliseconds, $\mathrm{FOV}=23$ $\mathrm{cm}, 6 \mathrm{~mm}$ slice thickness, matrix size $=256 \times 512)$; axial gradient-echo FLAIR* -weighted (TR=707 milliseconds, $\mathrm{TE}=23$ milliseconds, flip angle of $15^{\circ}, \mathrm{FOV}=23 \mathrm{~cm}, 6 \mathrm{~mm}$ slice thickness, matrix size $=205 \times 256$ ); inversion recovery (IR) T1-weighted (TR=5620 milliseconds, TE=17 milliseconds, inversion time $\mathrm{TI}=400$ milliseconds) and fluid attenuated inversion recovery (FLAIR) (TR=8000 milliseconds, $\mathrm{TE}=150$ milliseconds, $\mathrm{TI}=2350$ milliseconds) with the same section thickness, FOV and matrix ( $3 \mathrm{~mm}$, $23 \mathrm{~cm}, 256 \times 512)$ in the coronal planes perpendicular to the long axis of hippocampus, including the totality of the temporal lobe; fast field echo (FFE) T1-weighted (TR=30 milliseconds), $\mathrm{TE}=4.6$ milliseconds, one acquisition average pulse sequence, flip angle $=45^{\circ}, \mathrm{FOV}=23 \mathrm{~cm}, 1.5 \mathrm{~mm}$ slice thickness with no gaps, matrix size $=228 \times 512$, in the coronal plane. The control group underwent only the coronal FLAIR and FFE T1-weighted sequences.

MRI quantitative analysis - Three FLAIR (20\% gap, $3 \mathrm{~mm}$ thickness) slices including hippocampal head, body and tail on the coronal plane (perpendicular to the hippocampal axis) were taken from both groups. Hipocampal signal was accessed using Leonardo, Syngo MR 2004A (Siemens Medical Solutions, Erlangen, Germany). The signal was also measured using the same procedure in the pons of each patient, from both groups. This procedure was done to "normalize" variations between signals in different MRI as internal standard. Thus, final signal from hippocampal head, body and tail was ever considered as the ratio between its proper signals and those obtained from the pons of the same subject. All hippocampal and pons delimitations were made by the same neuroradiologist.

\section{Glutamate quantification}

The hippocampi were immediately removed and kept in a cryogenic vial, frozen in liquid hydrogen and stored at $-80^{\circ} \mathrm{C}$, and then weighted. The high performance liquid chromatography (HPLC) was performed using the 
method described by Cavalheiro ${ }^{18}$ with few modifications as follow: tissue was ultrasonically homogenized in a perchloric acid $0.1 \mathrm{M}, 0.02 \%$ sodium disulfide and homoserine $10 \mathrm{mg} / \mathrm{ml}$ solution (as internal standard). The homogenate was done in a proportion of $15 \mu \mathrm{L}$ solution for each milligram of wet tissue. The samples were kept at $0^{\circ} \mathrm{C}$ overnight and then centrifuged at $11.000 \mathrm{~g}$ at $4^{\circ} \mathrm{C}$ for 50 min. The supernatant was filtered and submitted to a reaction with O-phthaldialdehyde (OPA) and then injected into HPLC systems. Amino acid reaction was done dissolving $27 \mathrm{mg}$ of OPA in $1 \mathrm{~mL}$ of methanol, adding $5 \mu \mathrm{L}$ of 2-mercaptoetanol and $9 \mathrm{~mL}$ of sodium tetraborate 0.1 $\mathrm{M}$ (pH 9.3) solution.

Before sample analysis a solution was prepared with $1 \mathrm{~mL}$ of stock solution with $2 \mathrm{~mL}$ of sodium tetraborate $0.1 \mathrm{M}$. The pre column derivatization was completed by reacting $100 \mu \mathrm{L}$ of this solution with $50 \mu \mathrm{L}$ of amino acid standard solution for exactly 2 minutes before the injection on analytic column.

An isocratic HPLC system coupled to a fluorescence detector, a sample injector of $20 \mu \mathrm{l}$ for HPLC and a column RP-18 50×4.6 mm were utilized (Chromolith SpeedROD, Merch, Darmstadt). The mobile phase consisted of sodium phosphate buffer $0.05 \mathrm{M}$ (pH 5.95) with methanol $11.5 \%$. The flow rate was $3.5 \mathrm{ml} /$ minute, detection with excitation of $348 \mathrm{~nm}$ and emission of $460 \mathrm{~nm}$ in the fluorescence detector were employed. For standard chromatogram amino acid of known concentration were assayed and the retention time of each amino acid was verified for no overlapping after sample delivery.

\section{Nissl staining and immuno-histochemistry}

Brain tissues removed during surgery or autopsy were rapidly immersed in buffered ( $\mathrm{pH}=7.4) 1 \%$ paraformaldehyde, for $24 \mathrm{~h}$ at $4^{\circ} \mathrm{C}$. Collected hippocampi were sliced in $0.5 \mathrm{~cm}$ sections through longitudinal axis. All tissues were then dehydrated by an ethanol series, followed by xylol (100\%) before inclusion in paraffin. The paraffin included tissue was sliced $(3 \mu \mathrm{m})$ in microtome (Leica) and kept in silane-covered slides. After paraffin removal $(n=3)$, sections from the hippocampus were submitted to the classical Nissl staining (NS). Cresyl-violet staining was done to assess the specimen orientation and to check the localization and the extent of the lesion, being possible the classification of the sclerosis types as described by Blumcke ${ }^{17}$. In summary, five distinct pathological patterns were recognized after histological analysis: no MTS="no hippocampal cell loss , MTS type 1a=classic hippocampal sclerosis , MTS type $1 \mathrm{~b}=$ severe hippocampal sclerosis , MTS type $2=$ CA1 sclerosis, and MTS type $3=$ end folium sclerosis. Adjacent sections were selected for immuno-histochemistry $(\mathrm{n}=3)$.

Paraffin was removed from slices using 100\% xylol and endogenous peroxidases were blocked with $3 \% \mathrm{H}_{2} \mathrm{O}_{2}$, for $15 \mathrm{~min}$. After this procedure, the slices were submitted to $10 \mathrm{~min}$ of heating in microwave oven. Tissues were blocked using $5 \%$ bovine albumin during $90 \mathrm{~min}$ and incubated in humid chamber with primary monoclonal anti-human IL1 $\beta$, TNF $\alpha$ (1:50) (BD Bioscience, Minneapolis, USA) and CD45 (1:500) (DAKO clone PD7/26) antibodies for 48 hours in the presence of $1 \%$ milk. Following three washes in PBS, the sections were incubated with the secondary antibody (anti-mouse (1:500) from Calbiochem, Merck KGaA, Darmstadt, Germany). Immunodetection was performed using the Vectastain ABC Elite Kit (Vector Burlingame, CA, USA) and the complex antigenantibody was visualized using diaminobenzidine in PBS and $\mathrm{H}_{2} \mathrm{O}_{2}(1 \mu \mathrm{L} / \mathrm{mL})$. Tissue sections were mounted on glass slides and the material was examined with a microscope using bright-field illumination.

\section{Quantification of IL1 $\beta$ and TNF $\alpha$}

Tissues were homogenized in $0.01 \mathrm{M}$ tris- $\mathrm{HCl} \mathrm{pH} \mathrm{7.6,}$ $0.001 \mathrm{M}$ EDTA, nonidet P-40) $10 \%$ glycerol, $0.1 \mathrm{M} \mathrm{NaCl}$ buffer, containing a cocktail of protease inhibitors (Sigma Aldrich Corporation, St Louis, USA). The tissues were homogenized by ultrasound (Virsonic 60, Virtis) and stored at $-80^{\circ} \mathrm{C}$ until assay. Total protein was quantified using method described by Lowry ${ }^{19}$. A standard curve of both cytokines was done to find the liner range of Elisa (BD Bioscience OprEI ${ }^{\mathrm{TM}}$ ) method. After this procedure, different amount of cerebral tissues were assayed and 80 $\mathrm{pg} / \mathrm{ml}$ of protein from all sample homogenates were used due to its inclusion in liner range of the method. All assays were done in duplicate. The assays were done according to method described by manufacturer Kits (Human IL -1 ELISA Kit BD Opteia ${ }^{\mathrm{TM}}$ e Human TNF ELISA Kit BD Opteia $^{\mathrm{TM}}$ ). The optical density was measure at $450 \mathrm{~nm}$ in an Elisa reader equipment $\mu$ Quant Biotek (USA) and after using the software GEN 5 the concentration of IL1 $\beta$ and TNF $\alpha$ in each sample was determined. The concentrations were expressed in $\mathrm{pg} / \mathrm{mg}$ protein.

\section{Nitric oxide quantification}

After tissue removal all hipocampi (control and epileptic) were separated and frozen in liquid nitrogen in less of 20 seconds. The samples were homogenized in Tris$\mathrm{HCl}$ buffer containing $0.2 \mathrm{M}$ of $\mathrm{KCl}$ being submitted to a centrifugation at $10000 \mathrm{~g}$ during $10 \mathrm{~min}$ at $4^{\circ} \mathrm{C}$. To $1 \mathrm{~mL}$ of supernatant were added $2 \mathrm{ml}$ of $\mathrm{NaOH} 0.5 \mathrm{M}$ and 2 $\mathrm{mL}$ of $\mathrm{ZnSO}_{4}, 10 \%$. This mixture was homogenized during 30s and stayed at room temperature during $15 \mathrm{~min}$. A new centrifugation was done at $10000 \mathrm{~g}$ during $10 \mathrm{~min}$ e the NO concentration in each sample was quantified using Nitric Oxide Analyzer (NOA ${ }^{\mathrm{TM}} 280$, Sievers Instruments, Inc, Boulder, CO, USA) by chemiluminescence as 
described ${ }^{20}$. This method is highly sensitive and $1 \mathrm{pMol}$ can be detected. The concentrations in all samples were expressed as $\mu \mathrm{Mol} / \mathrm{mg}$ wet tissue.

\section{Statistical analysis}

To compare IL1 $\beta$, TNF $\alpha$ and glutamate concentration between epileptic and control groups Student $t$ test was employed. To analyze the existence of correlation between two different variables the linear correlation of Pearson was employed. For this purpose the software Statistical Package for Social Sciences (SPSS) version 11.0 for Windows was used. A $\mathrm{p}<0.05$ value was accepted as significant.

\section{RESULTS}

The Table summarizes all clinical data concerning to patients submitted to cortico-amygdalo-hippocampectomy at the Hospital São Paulo (UNIPETE/SPDM) including sex, age at surgery, presence of initial event, duration of epilepsy, brain side involved, presence of hyperintense signal in temporal pole structures, Engel's scale after surgery and type of sclerosis, according to Blumcke classification ${ }^{17}$.

In this context, the Engel's distribution between patients was $55.2 \%$ as IA, $10.3 \%$ as IB, $24.1 \%$ as IIIA, $3.4 \%$ as IVA, $3.6 \%$ as IIIB and 3.4 as IVC showing that a great majority of patients presented improvement in their quality of life after surgery, due to minor seizure episodes.

Table. Clinical data of patients submitted to cortico-amygdalo-hippocampectomy.

\begin{tabular}{|c|c|c|c|c|c|c|c|c|c|}
\hline No & Sex & Age & Initial event & Age of begin & $\begin{array}{c}\text { Duration/ } \\
\text { years }\end{array}$ & Side & $\begin{array}{c}\text { Temporal pólo } \\
\text { hypersignal }\end{array}$ & Engel scale & $\begin{array}{c}\text { Sclerosis } \\
\text { type }\end{array}$ \\
\hline 1 & $F$ & 38 & + & 10 & 28 & L & - & IB & - \\
\hline 2 & M & 39 & + & 7 & 32 & L & + & $\mathrm{IA}$ & - \\
\hline 3 & $\mathrm{~F}$ & 38 & + & 26 & 12 & $L$ & + & $\mathrm{IA}$ & - \\
\hline 4 & M & 28 & - & 25 & 3 & L & - & $\| I I A$ & IA \\
\hline 5 & $\mathrm{~F}$ & 38 & - & 7 & 31 & $L$ & + & $\mid A$ & $\mathrm{IB}$ \\
\hline 6 & $M$ & 28 & + & 14 & 14 & $\mathrm{R}$ & - & IA & $\mathrm{IB}$ \\
\hline 7 & $\mathrm{~F}$ & 29 & + & 24 & 5 & $L$ & - & IA & $\mathrm{IB}$ \\
\hline 8 & $\mathrm{~F}$ & 31 & + & 15 & 16 & $\mathrm{R}$ & - & IVA & - \\
\hline 9 & $\mathrm{~F}$ & 19 & - & 8 & 11 & $L$ & + & $\mid A$ & IA \\
\hline 10 & $\mathrm{~F}$ & 20 & - & 15 & 5 & $L$ & - & IIIA & AT \\
\hline 11 & $\mathrm{M}$ & 39 & - & 15 & 14 & $L$ & + & $\mid A$ & $\mathrm{IB}$ \\
\hline 12 & $\mathrm{~F}$ & 39 & - & 22 & 17 & $L$ & - & IA & AT \\
\hline 13 & $\mathrm{M}$ & 41 & + & 23 & 18 & $\mathrm{R}$ & - & IVC & $\mathrm{IB}$ \\
\hline 14 & $\mathrm{M}$ & 46 & + & 12 & 34 & $\mathrm{~L}$ & - & IIIA & $\mathrm{IB}$ \\
\hline 15 & F & 30 & - & 5 & 25 & $L$ & + & $\| I B$ & IA \\
\hline 16 & $M$ & 38 & - & 33 & 5 & $\mathrm{R}$ & - & $\| I I A$ & - \\
\hline 17 & $M$ & 32 & - & 7 & 25 & $L$ & - & $\mathrm{IB}$ & IA \\
\hline 18 & $\mathrm{~F}$ & 26 & - & 21 & 5 & $\mathrm{~L}$ & - & $\mid A$ & - \\
\hline 19 & F & 30 & - & 8 & 22 & $\mathrm{R}$ & + & IIIA & $\mid A$ \\
\hline 20 & F & 41 & - & 1,5 & 40 & L & - & IA & $\mathrm{IA}$ \\
\hline 21 & $\mathrm{~F}$ & 39 & - & 26 & 13 & $L$ & - & $\| I I A$ & AT \\
\hline 22 & $\mathrm{~F}$ & 51 & + & 16 & 35 & $L$ & - & IA & - \\
\hline 23 & $\mathrm{~F}$ & 35 & + & 7 & 28 & $\mathrm{R}$ & - & IA & - \\
\hline 24 & F & 31 & + & 0.8 & 30 & $\mathrm{R}$ & - & IA & $\mathrm{IB}$ \\
\hline 25 & F & 48 & - & 6 & 42 & $L$ & - & $\mid A$ & - \\
\hline 26 & $\mathrm{~F}$ & 56 & - & 27 & 29 & $L$ & - & IIIA & AT \\
\hline 27 & $\mathrm{~F}$ & 44 & - & 13 & 31 & $L$ & - & $\mathrm{IB}$ & - \\
\hline 28 & $\mathrm{~F}$ & 46 & - & 23 & 23 & $L$ & - & IA & IA \\
\hline 29 & $\mathrm{~F}$ & 49 & - & 7 & 42 & $R$ & + & IA & - \\
\hline
\end{tabular}

M: male; F: female; Age: at surgery intervention; Initial event: presence of febrile seizures or status epilepticus; Durantion: duration of epilepsy in years; Side: side with major involvement; Engel scale: Engel classification after surgery and sclerosis types: according to (8) classification; IA: type IA; IB: type IB; AT: atypical hippocampal sclerosis. 

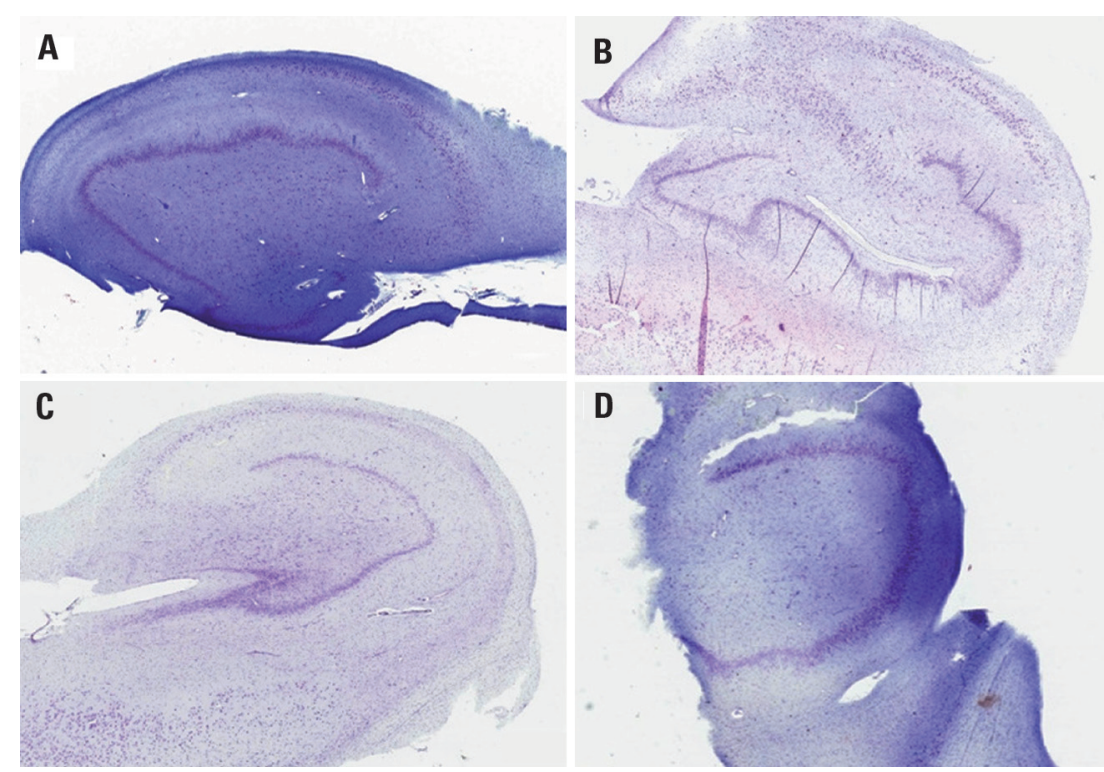

Fig 1. Hippocampal sclerosis. Nissl staining of hippocampus of patients with TLE and HS [A] Patient number 5 with HS Type 1B (scale bar $1000 \mu \mathrm{m})$. [B] Patient number 13, HS Type 1B (scale bar $1000 \mu \mathrm{m}$; Cresil). [C] Patient number 12, atypical HS; [D] HS without classification.
After Nissl staining, the types of hippocampal sclerosis were identified as shown in Fig 1, panel A, B, C and D. The Fig $1 \mathrm{~A}$ and $\mathrm{B}$ shows the stained tissue from patients presenting $\mathrm{HS}$ type $1 \mathrm{~B}$. Fig $1 \mathrm{C}$ shows an atypical HS (AT) and in the Fig 1D we can visualize an unclassified HS due to damage of the tissue during surgery.

The quantification of IL1 $\beta$ by ELISA method in sclerotic and autopsy/control hippocampi showed values of $117.6 \pm 15.4$ and $92.3 \pm 28.8 \mathrm{pg} / \mathrm{mg}$ protein $(\mathrm{p}=0.023)$ re-

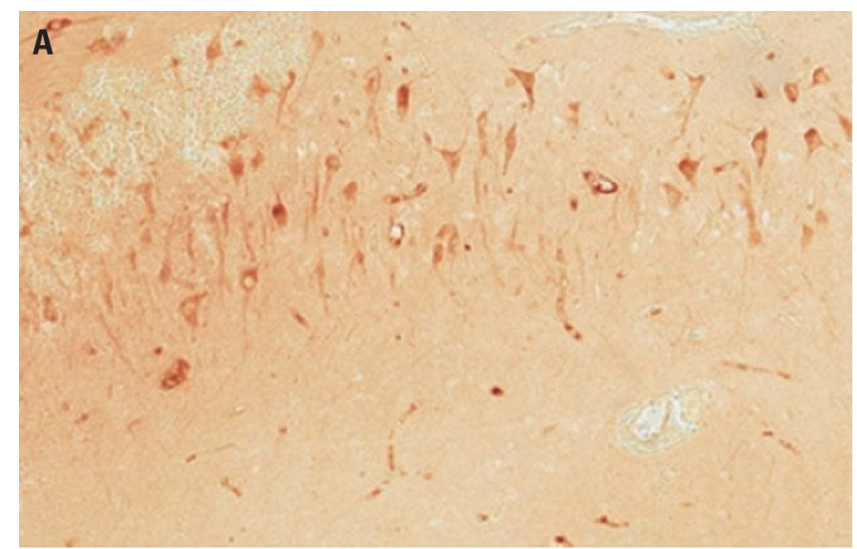

Fig 2. Immunohistochemistry (IL1 $\beta$ ). IL $1 \beta$ immunohistochemistry of patients 5 and 9 and autopsy/control tissue. [A] Patient number 9, CA2-CA3 regions (scale bar $100 \mu \mathrm{m}$ ). [B] Patient number 5, CA2- CA3 regions (scale bar $100 \mu \mathrm{m} ;[\mathrm{C}]$ Autopsy/control tissue CA2-CA3 regions (scale bar $100 \mu \mathrm{m} ; \mathrm{IL} 1-\beta$ ). spectively. The levels of TNF $\alpha$ obtained in both groups were $28.9 \pm 14.5$ (sclerotic hippocampi) and $17.8 \pm 16 \mathrm{pg} /$ mg protein (autopsy/control tissue) $(\mathrm{p}=0.049)$, showing increased concentration of both cytokines in the hippocampi of patients with TLE. These findings could be visualized and confirmed, in part, through the immuno-histochemistry analysis of IL1 $\beta$. The immuno-histochemistry done against IL1 $\beta$ in autopsy/control and sclerotic hippocampus is shown in Fig 2. The panels A and B show
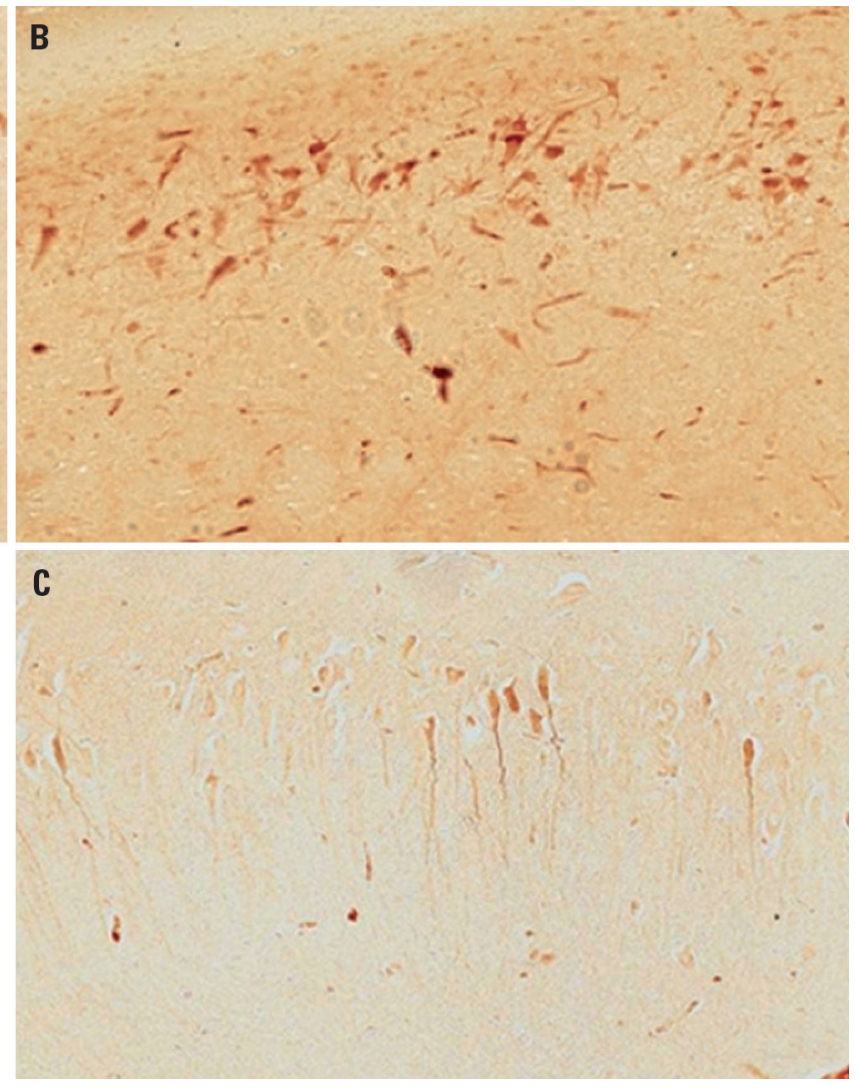

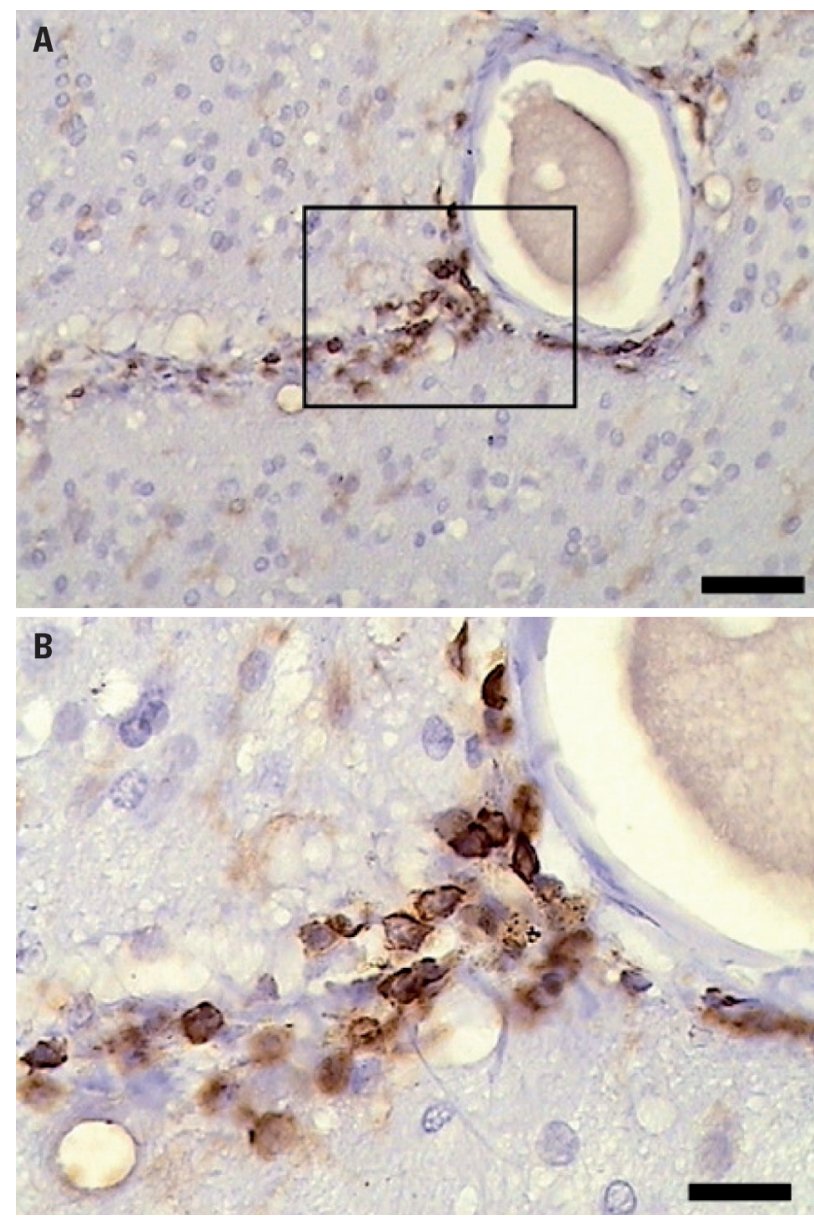

Fig 3. Imminohistochemistry (CD45). [A] Immunohistochemistry against CD45 showing lymphocytes in peri-vascular fashion (scale bar $50 \mu \mathrm{m}, \mathrm{CD} 45)$. [B] CD-45 amplification (scale bar $10 \mu \mathrm{m}$ ).

CA2 and CA3 regions from the hippocampus of two different patients. Panel $\mathrm{C}$ shows an autopsy/control tissue submitted to the same staining procedure. As can be visualized, there is an increased expression of IL1 $\beta$ in HS, when compared with the same regions of autopsy/control tissue. Immuno-histochemistry done with TNF $\alpha$ did not show difference between autopsy/control and sclerotic hippocampus (data not shown).

The amino acids levels in sclerotic and autopsy/control tissues demonstrated decreased concentration of glutamate in patients $(4.76 \pm 1.17 \mathrm{ng} / \mathrm{mg}$ wet tissue), when compared with autopsy/control tissues $(6.31 \pm 0.83 \mathrm{ng} / \mathrm{mg}$ wet tissue, $\mathrm{p}=0.00051$ ).

A presence of perivascular lymphocytes infiltrate could also be identified in Fig 3, when the tissues were submitted to immunostaining against CD45 antibody. This infiltrate could not be visualized in autopsy/control tissues.

A positive correlation was found between the level of IL1 $\beta$ and the signal presented in the tail of hippocampus as shown in Fig 4 (top panel) ( $\mathrm{p}=0.033$, Pearson co-

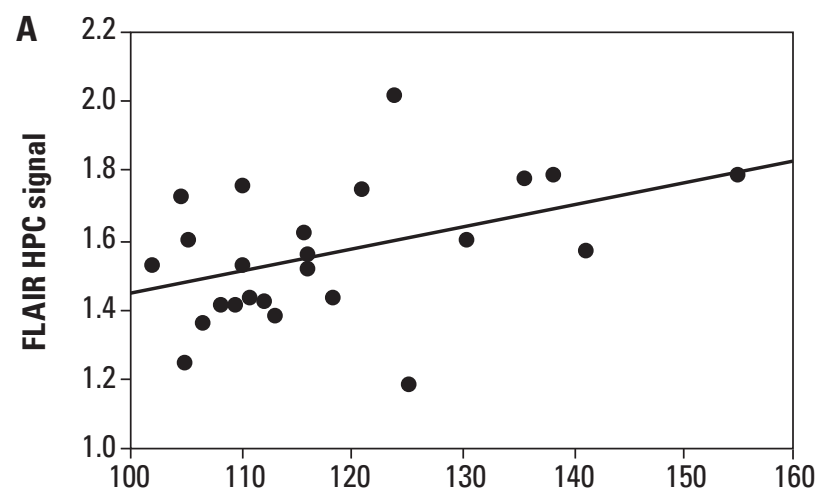

IL $\beta$ concentration

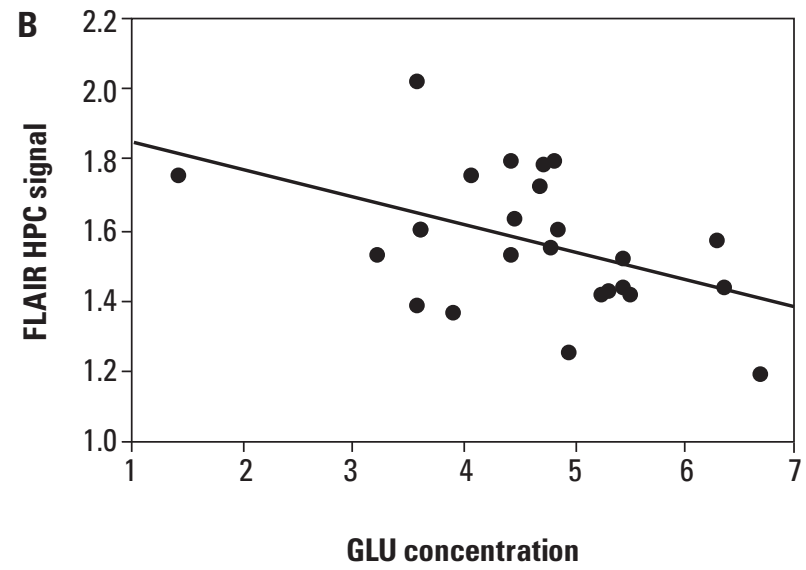

Fig 4. Correlation between Hippocampal FLAIR signal and IL $1 \beta$ and glutamate concentrations. [A] Hippocampal FLAIR signal versus IL1 $\beta$ concentration. [B] Hippocampal FLAIR signal versus glutamate concentration.

efficient $=0.436$ ). In contrast, a negative correlation was found between glutamate levels and FLAIR MRI signal intensity in hippocampal tail ( $\mathrm{p}=0.025$, Pearson coefficient $=0.457$ ) as shown in Fig 4 (lower panel).

No relationship between the levels of TNF $\alpha$ and FLAIR MRI signal intensity in head, body and tail of the hippocampus of patients with TLE was found, showing no association between these variables (data not shown). In addition, a positive correlation was found analyzing NO concentration and the FLAIR MRI signal intensity in the head (Pearson coefficient $=0.498, \mathrm{p}=0.013$ ); body (Pearson coefficient $=0.505, \mathrm{p}=0.012$ ) and tail of the hippocampus of patients with epilepsy (Pearson coefficient= 0.532, $\mathrm{p}=0.007$ ) (Fig 5).

\section{DISCUSSION}

The present work showed changes in the concentration of different inflammatory mediators such as IL1 $\beta$ and TNF $\alpha$ in the hippocampus of patients with MTS. In addition, a decreased glutamate concentration was also found, when compared with autopsy/control tissues. The mea- 

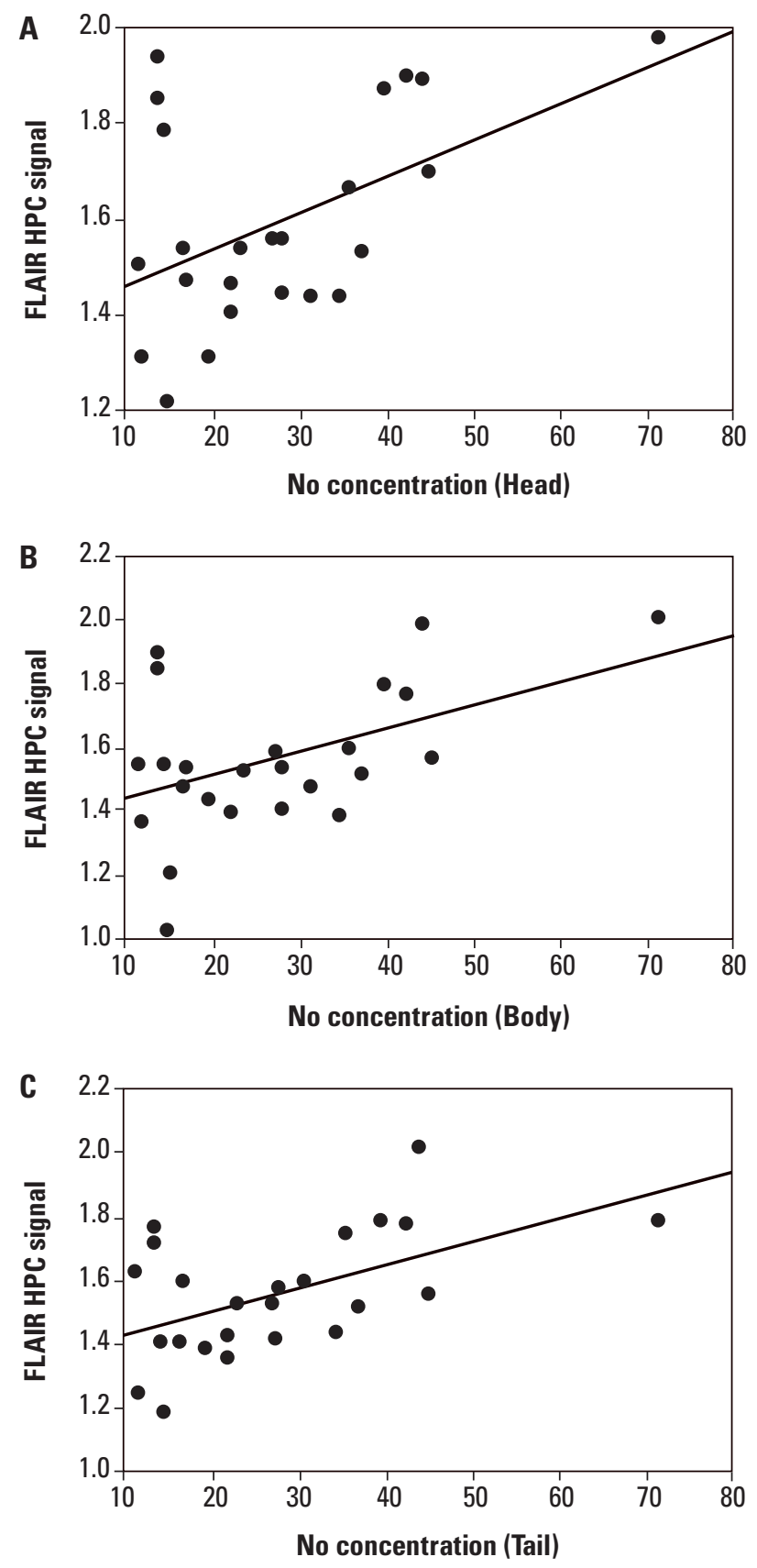

Fig 5. Hippocampal FLAIR signal and NO concentration. [A] FLAIR signal from hippocampal head versus NO concentration. [B] FLAIR signal from hippocampal body versus NO concentration. [C] FLAIR signal from hippocampal tail versus NO concentration.

surement of cytokines $\mathrm{NO}$ and glutamate was done in the head of the hippocampus since Bernasconi et al. ${ }^{8}$ described this region as that responsible for the major signal alteration on MRI. We also found a linear relationship between cytokines and NO levels with the signal on FLAIR MRI in head, body and tail of the hippocampus.

These data suggest the presence of an inflammatory process in the hippocampus, associated with increased release of glutamate, which is indicative of a persistent excitotoxicity. Our data are supported by previous report $^{21}$, which demonstrated increased extracellular glutamate levels (increased release), using microdialysis probes in humans with TLE. A deficiency in glutamine synthesis in astrocytes, found by several authors ${ }^{22}$, can also explain the high levels of glutamate in extracellular space, suggesting increased release of this amino acid. Working with synaptosomes from hippocampus of patients with TLE and MTS, was found ${ }^{23}$ increased basal release of glutamate and GABA, data that could support our findings. Thus, the decreased concentration found in sclerotic hippocampus could be associated to increased release of this neurotransmitter, as already reported by several authors.

Cytokines, a diverse group of polypeptides that are generally associated with inflammation, immune activation, cell differentiation or death include interleukins, interferons, tumor necrosis factors, chemokines and growth factors ${ }^{24}$. Cytokines can exert direct action on neurons, indirect action via glial cell, direct action on brain vasculature and on physiological parameters such as regional blood flow and temperature. IL1 $\beta$ and TNF $\alpha$ act on distinct cell-surface receptors but share some common signaling mechanisms related to neurodegeneration. IL1 $\beta$ can induces cell death ${ }^{11}$, as well as cyclooxygenase 2 (COX2) and oxide nitric synthase overexpression (iNOS) ${ }^{24}$. In addition, seizures stimulate increase in the levels of IL1 $\alpha$, IL1 $\beta$, IL6 and TNF $\alpha$ in the brain ${ }^{25}$. The mechanism by which IL1 affect seizure activity is not known, but Allan ${ }^{26}$ showed that the association between administration of AMPA receptor agonist and IL1 produce widespread cortical cell death. This fact is not observed when AMPA or IL1 are administered alone ${ }^{26}$. This fact indeed support the hypothesis that suggest the participation of increased release of glutamate associated with the increased levels of cytokines, in the process of cell death, observed in the hippocampus of patients with TLE and MTS. Glutamate during excitotoxic phenomenon stimulates AMPA and NMDA receptors producing excessive depolarization of postsynaptic membrane, which results in an osmotic imbalance when countered by an influx of $\mathrm{Na}^{+}, \mathrm{Cl}^{-}$and water ${ }^{12}$.

Glial cells can also secrete IL1 $\beta$ and TNF $\alpha$, which in turn, can act on these cells in an autocrine manner. IL1 $\beta$ and TNF $\alpha$ induce the proliferation of astrocytes, a process known as astrogliosis ${ }^{11}$, which is also found in hippocampal sclerosis 6 .

The NO level from sclerotic hippocampus was correlated with FLAIR hyperintense signal in the head, body and tail of this structure, supporting the hypothesis of participation of NO production in the hippocampal sclerosis. Neuronal NOS is localized in the hypothalamic supraoptic and paraventricular nuclei, both of which are mainly involved in the neurosecretory activity of this 
area. $\mathrm{NO}$ is able to interact with many intracellular targets to trigger an array of signal transduction pathways, resulting in stimulatory or inhibitory output signals. However, it becomes noxious if it is produced in excess ${ }^{27}$. Recently the term "nitrosative stress" has been used to indicate the cellular damage that is elicited by excess of $\mathrm{NO}$ and reactive nitrogen species ${ }^{28}$. In addition, NO has been shown to stimulate the release of noradrenaline and glutamate in the hippocampus ${ }^{29}$. This data can support our hypothesis concerning to increased release of this neurotransmitter since we found low levels of glutamate in sclerotic tissues, when compared with autopsy/control tissues. Taken together, these data support the idea that the hyperintense signal on FLAIR MRI could be the result of increased expression of cytokines and $\mathrm{NO}$ associated with increased excitotoxicity in TLE.

The correlation between ipsilateral versus contralateral signals showed that although the hyperintense signal was major in the sclerotic side the contralateral hippocampus is frequently involved since it also presented increased FLAIR signal.

As lymphocytes were also visualized in epileptic tissue we can suppose that both humoral and cellular immune systems are activated in TLE associated with HS. This data were previously reported by other authors ${ }^{9,30-32}$, who demonstrate the presence of cytokines, complement activation as well and NO release in the blood after an ictal event.

Taken together, these data show the participation of markers of inflammatory process in the physiopathology and in FLAIR signal related to temporal lobe epilepsy, associated to hippocampal sclerosis.

The authors thank to Hilda Reis and Margaret Gori Mouro for their technical assistance as well as all clinicians involved in the treatment of the patients.

\section{REFERENCES}

1. Choi D, Na DG, Byun HS, et al. White-matter change in mesial temporal sclerosis: correlation of MRI with PET, pathology, and clinical features. Epilepsia 1999;40:1634-1641.

2. Mitchell LA, Jackson GD, Kalnins RM, et al. Anterior temporal abnormality in temporal lobe epilepsy: a quantitative MRI and histopathologic study. Neurology 1999;52:327-336.

3. Babb T. Pathological findings in epilepsy. 1 ed. New York: Raven Press; 1987.

4. Mathern GW, Adelson PD, Cahan LD, Leite JP. Hippocampal neuron damage in human epilepsy: Meyer's hypothesis revisited. Prog Brain Res 2002;135: 237-251.

5. Cendes F, Andermann F, Gloor P, et al. MRI volumetric measurement of amygdala and hippocampus in temporal lobe epilepsy. Neurology 1993;43: 719-725.

6. Cook MJ. MRI and epilepsy surgery. J Clin Neurosci 1996;3:325-326.

7. de Lanerolle NC, Lee TS. New facets of the neuropathology and molecular profile of human temporal lobe epilepsy. Epilepsy Behav 2005;7:190-203.
8. Bernasconi N, Bernasconi A, Caramanos Z, Antel SB, Andermann F, Arnold DL. Mesial temporal damage in temporal lobe epilepsy: a volumetric MRI study of the hippocampus, amygdala and parahippocampal region. Brain 2003;126:462-469.

9. Vezzani A, Granata T. Brain inflammation in epilepsy: experimental and clinical evidence. Epilepsia 2005;46:1724-1743.

10. Viviani B, Bartesaghi S, Gardoni F, et al. Interleukin-1 beta enhances NMDA receptor-mediated intracellular calcium increase through activation of the Src family of kinases. J Neurosci 2003;23:8692-8700.

11. Wang CX, Shuaib A. Involvement of inflammatory cytokines in central nervous system injury. Prog Neurobiol 2002;67:161-172.

12. Dong XX, Wang Y, Qin ZH. Molecular mechanisms of excitotoxicity and their relevance to pathogenesis of neurodegenerative diseases. Acta Pharmacol $\operatorname{Sin} 2009 ; 30: 379-387$

13. Brown GC, Bal-Price A. Inflammatory neurodegeneration mediated by nitric oxide, glutamate, and mitochondria. Mol Neurobiol 2003;27:325-355.

14. Clarkson AN, Liu H, Pearson L, et al. Neuroprotective effects of spermine following hypoxic-ischemic-induced brain damage: a mechanistic study. FASEB J 2004;18:1114-1116.

15. Gilad GM, Gilad VH, Casanova MF, Casero Jr RA. Polyamines and their metabolizing enzymes in human frontal cortex and hippocampus: preliminary measurements in affective disorders. Biol Psychiatry 1995;38:227-234.

16. Bloch-Boguslawska $E$. [The effect of the time of death on the reactivity of rat caudal artery regulated by NA with a simultaneous use of NOS, CG and COX inhibitors. Part I]. Arch Med Sadowej Kryminol 2006;56:136-143.

17. Blumcke I, Pauli E, Clusmann H, et al. A new clinico-pathological classification system for mesial temporal sclerosis. Acta Neuropathol 2007;113: 235-244.

18. Cavalheiro EA, Fernandes MJ, Turski L, Naffah-Mazzacoratti MG. Spontaneous recurrent seizures in rats: amino acid and monoamine determination in the hippocampus. Epilepsia 1994;35:1-11.

19. Lowry OH, Rosebrough NJ, Farr AL, Randall RJ. Protein measurement with the Folin phenol reagent. J Biol Chem 1951;193:265-275.

20. Hampl V, Walters CL, Archer SL. Determination of nitric oxide by the chemiluminescence reaction with ozone. In: Feelisch M, Stamler JS, (Eds). Methods in nitric oxide research. Chichester: John Wiley \& Sons; 1996:310-318.

21. Cavus I, Pan JW, Hetherington HP, et al. Decreased hippocampal volume on MRI is associated with increased extracellular glutamate in epilepsy patients. Epilepsia 2008;49:1358-1366

22. Eid T, Thomas MJ, Spencer DD, et al. Loss of glutamine synthetase in the human epileptogenic hippocampus: possible mechanism for raised extracellular glutamate in mesial temporal lobe epilepsy. Lancet 2004;363:28-37.

23. Hoogland G, Hens JJ, De Wit M, et al. Glutamate and gamma-aminobutyric acid content and release of synaptosomes from temporal lobe epilepsy patients. J Neurosci Res 2000;60:686-695.

24. Allan SM, Rothwell NJ. Cytokines and acute neurodegeneration. Nat Rev Neurosci 2001;2:734-744.

25. Jankowsky JL, Patterson PH. The role of cytokines and growth factors in seizures and their sequelae. Prog Neurobiol 2001;63:125-149.

26. Allan SM, Rothwell NJ. Cortical death caused by striatal administration of AMPA and interleukin-1 is mediated by activation of cortical NMDA receptors. J Cereb Blood Flow Metab 2000;20:1409-1413.

27. Calabrese V, Mancuso C, Calvani M, Rizzarelli E, Butterfield DA, Stella AM. Nitric oxide in the central nervous system: neuroprotection versus neurotoxicity. Nat Rev Neurosci 2007;8:766-775.

28. Guix FX, Uribesalgo I, Coma M, Munoz FJ. The physiology and pathophysiology of nitric oxide in the brain. Prog Neurobiol 2005;76:126-152.

29. Lonart G, Wang J, Johnson KM. Nitric oxide induces neurotransmitter release from hippocampal slices. Eur J Pharmacol 1992;220:271-272.

30. Aronica E, Boer K, van Vliet EA, et al. Complement activation in experimental and human temporal lobe epilepsy. Neurobiol Dis 2007;26:497-511.

31. Bauer S, Cepok S, Todorova-Rudolph A, et al. Etiology and site of temporal lobe epilepsy influence postictal cytokine release. Epilepsy Res 2009:86:82-88.

32. Carmeli E, Beiker R, Morad M. Nitric oxide and interlukin-6 levels in intellectual disability adults with epilepsy. Res Dev Disabil 2009:30:567-571. 